\title{
From physical spaces to learning environments: processes in which physical spaces are transformed into learning environments
}

\author{
Anna Kristiina Kokko ${ }^{1}$ (D) Laura Hirsto ${ }^{1}$
}

Received: 1 July 2019 / Accepted: 30 April 2020 / Published online: 16 May 2020

(C) The Author(s) 2020

\begin{abstract}
The aim of this study was to gain a better understanding of the change from physical spaces to learning environments by examining how, and through which processes, learning spaces are transformed, produced and developed. For this purpose, we used a comparative ethnography approach and collected observation material from two Finnish schools at different development phases. The material was supplemented by focus-group interviews with teachers and individual interviews with principals. The results suggest that no ready-made models exist which fit into a new context. Rather, practices are constructed in physical spaces through active negotiations and meaning- making in three cyclic interaction processes (i.e., interaction between teachers, interaction between students and teachers, and interaction between students). Hence, through cyclic processes with strong support from teachers, students managed to find tools to build learning environments suited to their needs, which further enabled the expansion of learning environments inside and outside school walls. Nevertheless, changes in practices required an overall change in every aspect of the school. Focusing on the processes of change, results provide information from a systemic perspective on how schools can manage continuous change when developing physical spaces into learning environments.
\end{abstract}

Keywords Change processes · Comparative ethnography $\cdot$ Learning environments · Learning spaces $\cdot$ Relational approach

\section{Introduction}

New modern school buildings are designed to meet the needs of twenty-first century learners and to facilitate, for instance, flexibility in teaching and learning, collaboration and critical thinking (Benade 2016). Therefore, continuous development of individual and student-centred learning environments has become a relevant research topic (e.g., Dovey and Fisher 2014; Hirsto 2018). Previous empirical research has revealed the potential of

Anna Kristiina Kokko

anna.kokko@uef.fi

1 School of Applied Educational Science and Teacher Education, University of Eastern Finland, Joensuu, Finland 
open and flexible physical learning spaces by measuring the impact of different spatial layouts on teacher practices and students' learning experiences (Barret et al. 2015; Brooks 2011; Byers et al. 2014, 2018; Imms and Byers 2017). However, even researchers have not accumulated vital understanding of positive outcomes in open and flexible physical spaces; despite good design, spaces themselves do not always cause a shift in pedagogy, and how the actual change is achieved has remained unclear (cf. Blackmore et al. 2010; Campbell et al. 2013; Leiringer and Cardellino 2011; Mulcahy et al. 2015; Woolner et al. 2018). Therefore, the aim of this study was to contribute to the gap in the literature by examining how, and through which processes, learning spaces are transformed, produced and developed.

\section{Theoretical framework}

The term learning environment is regularly defined as a social, psychological or conceptual setting rather than the physical learning space (Cleveland 2009). In their wider form, learning environments are considered to "happen anywhere and at any time" (Brown and Lippincott 2003). In addition, learning environments are often defined as consisting of pedagogy, technology and physical space, where the physical is an example of ideals, but the dialogue between different factors is what matters (Cleveland and Fisher 2014; Radcliffe 2008).

To understand the processes of change, the underpinning theoretical premise of this study draws on relational and sociomaterial approaches in which learning spaces are not seen just as physical buildings where learning occurs, but rather as a site for collaboration and continued negotiations between the physical and the social (Lefebvre 1991; Massey 2005; Mills and Comber 2015). In other words, spaces are seen to be produced in heterogeneous relations, which generate and is generated by interaction (Boys 2011; McGregor 2004, p. 2), and in which material (i.e., physical space, technology, and the curriculum) becomes visible in social relations (Fenwick 2012; Mulcahy et al. 2015). Moreover, in the relational approach, learning spaces are not understood as given or fixed, but rather as temporal processes, which provide the opportunity to see spaces as an ongoing series of redesigns always under construction (Massey 2005). Therefore, space should be considered more as a verb than a noun, because it is more what we do, not something we have (Mulcahy et al. 2015).

Previous research has studied change from traditional classrooms to open and flexible learning spaces by questioning how physical spaces are used and how they shape teachers' practices (Alterator and Deed 2013, 2016; Campbell et al. 2013; Chapman et al. 2015; Kariippanon et al. 2018). Yet, transition to open and flexible spaces does not often operate without challenges, with both teachers and students requiring support during the change (Kariippanon et al. 2018; Saltmarsh et al. 2015). Overall, the maturity of change depends on the constancy of routines and the level of pedagogical certainty (Deed and Lesko 2015).

Related to the sociomaterial approach, there is a strong corpus of empirical research highlighting that physical learning spaces are encompassed within multiple sets of relations and practices (McGregor 2004; Mulcahy et al. 2015). According to Mulcahy et al. (2015), achieving the change processes requires continued negotiations in which the school community challenges the cultural meanings embedded in practices (Alterator and Deed 2016; Mulcahy 2018; Woolner et al. 2012). Social relations between teachers have been investigated because teachers' professional learning communities provide multiple opportunities for professional development (Owen 2016; Watson 2014) and learning from each other (Campbell et al. 2013). 
Moreover, changes in practices have also been studied by fluid negotiations between teachers and students and among students (e.g. Chapman et al. 2015). For instance, Woolner et al. (2012) observed that teachers' and students' perspectives on practices can vary, creating situations in which teachers' intentions do not always lead to desired outcomes from the students' perspective. In turn, negotiations of pedagogical choices can facilitate students' and teachers' self-managed ownerships over the learning process (Deed et al. 2015) or agency (Ryan and Deci 2000). The relations between teachers and students have also been studied through 'structures', which in this study are defined in a relational way as culturally-produced practices rather than pre-existing structural conditions (Saltmarsh et al. 2015). Yet, even the structures have been considered to be useful. To avoid too much performativity, it is important to avoid over-stressing the need for structures and, with the right balance, there is an opportunity for students' and teachers' co-production of space (Davies et al. 2013; Saltmarsh et al. 2015).

A broader understanding of structures encompasses the school rules and culture (Gislason 2010; Woolner et al. 2018), as well as structures as a product of meaning-making processes (i.e., shared vision) (Mulcahy et al. 2015). This perspective is in line with other recently-published research, which has emphasised that learning spaces should be investigated in relation to the different aspects of school (Boys 2011, p. 81; Newland et al. 2019). Thereby, examinations concerning learning spaces can be expanded to the synthetic approach of systems thinking which emphasises the meaning of context, in which relations can shape the constituent parts in two-way reciprocal relations. For instance, Hirsto $(2013,2018)$ used a systemic approach and defined the three key processes when developing learning environments. These processes pass through different levels of schools and include curriculum work, development of teachers' skills, and strategic processes.

\section{Investigating change}

In previous studies, change in learning spaces has been investigated through, for instance, ethnographic observations and interviews (Campbell et al. 2013; Chapman et al. 2015; Saltmarsh et al. 2015), repeated measures (Byers et al. 2014) and participant methods (Mäkelä et al. 2018; Woolner et al. 2012, 2018). Because different methods provide complementary results and different perceptions do not always align with each other, recent research has emphasized the meaning of connecting different methods and perspectives (Cipriano et al. 2019; Cleveland and Fisher 2014; Lee and Tan 2011; Newland et al. 2019; Scherzinger and Wettstein 2019).

\section{Current study}

The aim of this study was to investigate how, and through which processes, learning spaces are transformed, produced and developed. For this purpose, we identified three research questions. (1) What kind of change processes can be identified from the data? (2) How do the explored processes continue to evolve? (3) What are the boundaries and facilitators of change? 


\section{Methods}

\section{Context of the study}

The framework of relational space requires that the methods and cases are selected to be suitable for investigation of different relationships and change over time (Taylor 2013). In order to understand the dynamics of change processes, and how people in different places manage similar challenges, we applied a comparative ethnography approach for this study (Laurie 2012, p. 500; Picker 2017; Simmons and Smith 2019). When adopting sensibility of comparative ethnography at the research design, case selection does not have to be able to address potential alternatives through 'control' (Schatz 2009; Simmons and Smith 2017). Hence, it is more important to consider how processes and practices of different settings interact in a theoretically-relevant way and construct the dynamics which shape context (Simmons and Smith 2017).

Two Finnish schools which operated in new, technology-enhanced school buildings, but were at different development phases (socialisation phase and developed phase schools), were chosen. The developed school was founded in autumn 2016 and, at the beginning of the observation period, it had operated in the new school building for 2 years. The socialisation phase school was founded in autumn 2018 and moved into the new school building in January 2019. Observations in the socialisation phase school began as soon as the school started working in the new premises. Both schools were public primary schools (students aged 6-12 years). Yet, the socialisation phase school was part of a larger comprehensive school (students aged 6-16 years). Both schools started with a new, just-hired staff. Therefore, at the beginning, teachers were familiar with neither each other nor students. In addition, both schools were available to all children in their area and, therefore, they were not selective in terms of their student population.

The number of students in each learning space varied from 80 to 100 . Hence, the schools had smaller groups and classrooms for some students with special needs. Each learning space included two large spaces, at least one smaller group space, and a common area. In addition, the spaces were enhanced with moveable furniture and varying possibilities, such as privacy screens, to divide spaces. Teachers worked in teams of four to five people and, importantly, were assigned to the teams and did not choose the team in which they worked.

\section{Data production and participants}

The data were produced during one school year (2018-2019) and consisted of comprehensive field notes (FN) from participant observation in the learning spaces, six focus-group interviews of teachers $(n=30)$ and three individual interviews of principals $(n=3)$. The timeline for the data production is shown in Fig. 1.

$$
\begin{aligned}
& \text { Participant } \\
& \text { observations in the } \\
& \text { developed school }
\end{aligned}
$$

Focus-group discussions and principal interview in the developed school
Participant observations in the socialization phase school
Focus-group discussions and principal interview in the socialization phase school

Fig. 1 Timeline for the data production 
The purpose of participant observations was to explore "what people do in their everyday lives" (DeVault and McCoy 2002, p. 755). To reach the ongoing processes and reconstruction of space, observations were carried out for a total of 12 days and 36 lessons between October and December 2018 in the developed school's learning spaces, and from January to May 2019 for a total of 28 days and 96 lessons in the socialisation phase school's learning spaces. The socialisation phase school required a longer observation period, based on the assumption that the cultural and structural changes are more solid in the mature phase than in the socialisation phase.

In the next phase, the data was generated between researchers and participants (Hultin 2019) because the information received from the observations was used as a basis for interviews. The purpose of interviews was to explore what kind of meanings people give to their actions and to explore "how people make sense of their world" (Schatz 2009; Simmons and Smith 2019). Because the expressions of the same interpretative group can be seen as represented and reorganised in discourse (Bohnsack 2004), the focus-group interview method was chosen to simulate discussion and thereby pursue greater depth to the topic. The use of a semi-structured interview allowed modification of the questions concerning the situations, which had been raised from the observation material, and also the use of themes and narratives, through which we aimed to reach the temporal aspect concerning past events. In addition, in this way, interviewees could bring up any issues during the interview (Qu and Dumay 2011, p. 16). Interviews lasted 50-90 min, with a total of $9 \mathrm{~h}$ and $31 \mathrm{~min}$ of audiorecorded data being produced and transcribed.

\section{Data analysis}

As is typical in a comparative ethnography approach, instead of comparing differences and similarities, we aimed to explore the dynamics which shape school life and to pay specific attention to meanings embedded in physical spaces (Simmons and Smith 2017). Therefore, the focus and basis for the analysis, in comparison of processes and practices, were moving back and forth first within each case and afterwards between cases (Simmons and Smith 2019). Because ethnographic comparison assumes that a phenomenon is not completely theoretically controlled (Simmons and Smith 2017) and because the analysis started during the fieldwork, grounded theory approaches suggested by Charmaz $(1995,2016)$ and Straus and Corbin $(1994,1998)$ were applied for the analysis. These approaches do not require pure inductive analysis, but rather allow prior knowledge and concepts to guide the inquiry while searching for novel theoretical insights. To control the large amount of material from different sources, we utilised the Lefebvre's (1991) concepts of observed space (spatial aspects and practices in spaces), experienced space (personal experiences and meanings) and conceived space (school rules and visions) as analytical tools. Adopting these concepts as a basis for analysis helped to achieve a practical and nuanced examination of the dynamics of change processes in terms of a relational approach to space.

The data was analysed in three phases. In the first phase, the following question was posed: (1) what kind of change processes could be identified from the data? To answer this question, we identified the episodes in which routines of space were negotiated and challenged. In the second phase, and in order to answer the second research question, the data were scrutinised in terms of (2) how the explored processes continue to evolve-that is, what had changed or remained the same during the time spent in the new spaces and why. Finally, in the third and last phase, we aimed to identify (3) the boundaries and facilitators 
of change were. For this purpose, we identified the situations and elements which occurred as preventing or promoting change processes.

We also applied the idea of an intercoder reliability test (Cho 2008) using randomlyselected codes. First, the first author coded and categorised the qualitative material individually. Then, the second author categorised a sample of 50 codes. The original agreement rate in the analysis was $88 \%$. The two authors negotiated the codes that were difficult to categorise until they reached full agreement. This led to further development and explication of the boundaries within and between categories.

\section{Findings}

This section illuminates how, and through which processes, spaces are transformed, produced and developed. In the following, the results are divided into three sections in the order of the research questions. The first and second sections present the nascent and advanced processes through which teachers and students renegotiated new meanings for the physical spaces. By taking a systemic perspective to the construction of processes in the third section, we provide an insight into the qualities of the boundaries and facilitators for these processes.

\section{Nascent processes}

When previous cultural meanings did not fit into the new space, routines and the use of physical space were negotiated and challenged in combinations of social relations (social interaction processes) (1) between teachers, (2) between students and teachers and (3) between students. Because these social-interaction processes initially occurred separately from each other, they are called nascent processes. Although the examples in this section only include reference from the socialisation phase school's teachers, the same nascent processes could also be found in the narratives of the developed school's teachers.

\section{Social interaction between teachers}

Openness provided opportunities for diverse solutions for the use of physical space. However, openness itself did not make the space functional but, through negotiations between teachers, new meanings were given to the physical space. As a result, the spaces started to achieve a certain nascent flexibility for different practices. Some teachers, for example, did not teach together often, but "divided students into smaller groups and also supported this by dividing physical space to become suitable for groups" (FN200). These actions were typically intended "to offer the opportunity to use different pedagogies" (teacher 28 from the socialisation phase school). In these situations, the meanings given to physical space related to teachers' perspective of students' individual learning or their own individual ways of teaching. In turn, in the situations in which teachers arranged the physical spaces so that "all students are together in one large and open space" (FN188), meanings given to the physical spaces were initially related to teachers' professional learning. Here, teachers aimed to "teach together as much as possible because, in this way, it is possible for us to learn from each other" (teacher 20 from the socialisation phase school). These were not exclusive practices but rather they changed depending on the situation. In addition, through negotiations concerning the use of space, teachers could avoid the unfortunate 
situations in which one group undertook some quiet practices, such as reading, but got disturbed because, at the same time, another group was working with louder group-work in the shared spaces.

Nevertheless, when the new meanings for the use of physical space were only negotiated and produced between teachers, relations between teachers and students often seemed to be one-way interactions, with the result that students did not "participate in teachers' innovations or engage in the activities" (FN177). It seems that students would have naturally taken a more-active role in new spaces but became passive with pre-negotiated and fixed activities. In turn, the same pattern was also found in situations in which too much freedom without sufficient support prevented students' actions as "if the plan is to offer freedom for students but, if there is too much freedom to choose, some students are unable to act and feel emotional insecurity" (teacher 23 from the socialisation phase school). Overall, these situations were often related to expectations based on meanings that had been only negotiated between teachers, with the involvement of students being predefined to a certain type of behaviour, which therefore limited their individual participation and also their agency.

\section{Social interaction between students and teachers}

In the process of social interaction between students and teachers, negotiated together new meanings for physical space. Also, as a result of negotiations, the openness began to change into a certain nascent flexibility of space and practices but, unlike in the former process (interaction between teachers), the emphasis then was on students' ability to make their own choices, with 'teachers' continued support for students to choose how and where to work, by asking questions about their learning experiences" (FN198). Teachers often described these situations related to students, as well as their own emotional insecurity in new spaces: "In traditional spaces, where there are rows of desks and everyone has this one place where he/she is supposed to be, everyone knows what will happen and it feels safe. In these new spaces, it is like chaos, and I have tried to ask students what it is that brings the experience of security here (teacher 22 from the socialisation phase school). The examples show that, in this process, students actively participated in the negotiations of new meanings.

Conversely, when teachers did not share these ideas, students could participate in negotiations in one lesson, but not in the next class with another teacher. This was confusing for students and teachers and emerged in situations when "the level of students' and teachers' agency varied during the day and depending on the situation" (FN188). Therefore, these situations created different boundaries for students and teachers to participate.

\section{Social interaction between students}

New learning spaces offered students a range of informal and formal opportunities for negotiations to learn together and to share the day with friends. Students were continuously asked "to choose where to work" (FN220). Meanings for these situations related to "students' increasing agency to choose for themselves" (teacher 26 from the socialisation phase school). Thus, when the meanings for physical spaces were only negotiated between students, this often led to situations in which students negotiated new meanings, which were not the best solutions regarding the learning task. This was evident in situations where "the students were able to choose their own working space without negotiating the direction of the assignment and on what basis the space should be chosen" (FN201). Teachers reflected 
the issue of students' responsibility and freedom: "Even though I find it very important that every student can learn from each other, there have to be very precise instructions on how to work so that students do not just go out to talk to their friends or let the group do the task" (teacher 27 from the socialisation phase school). Therefore, when the use of the new facilities was not negotiated in relation to teachers, this could show the students as active agents and owners of their own learning even when they were not.

So far, the results have shown how reactions related to a changing environment transform into different but still independent processes of change. However, reactions to the new space did not always lead to negotiations. There were also situations in which teachers and students continued schoolwork with familiar routines and activities. In these situations, meanings related to space were typically tied to previous, more-traditional physical arrangements and, for instance, emotional security embedded to them. In addition, the interaction was usually more or less one-way and produced from one perspective. Therefore, the space was also seen as a limiting factor for pedagogical practices and students' agency.

\section{Advanced processes}

The development of processes was explored through the lens of what had remained the same, what had changed and why. In their more-advanced form, the three social interaction processes (i.e., social interaction between teachers, social interaction between students, and social interaction between teachers and students) remained the same, although they no longer functioned separately but formed a cyclical structure. At the same time, use of space was developed from being pre-structured to being more "structuring of space during activities" (FN44). Also, as described earlier, previous meanings related to the physical space did not concern students' emotional insecurity anymore but, through cyclical processes, emotional security was tied to students' ownership of their own learning. "This has developed so that we (the teachers) make the foundation through our pedagogical knowledge and goals, and the students then decide in their everyday lives how to implement it utilising different spaces individually and in groups, which we then guide and support in the best possible way. Shifting the focus to students' own learning kind of gives them emotional security. This requires a certain amount of student knowledge. When all four of us observe the day and unpack it together, it is a pretty good bunch of information" (teacher 4 from the developed phase school). Therefore, the information received from negotiations with students was used in the teachers' negotiations and further led to the continuous development of pedagogy, which was based on a vision of students' individuality and agency. Increased agency was evident during days and weeks when students continuously made decisions about their own learning concerning individual or group work, physical space, technology use, etc. This typically happened "with the strong support of the teachers, who had reflected the practices through the information received from the students" (FN66).

Importantly, at the same time when the cyclical nature of the three social interaction processes was emphasised to produce students' agency, teachers also emphasised the change in pedagogy and their own agency. "It is not always so obvious what students have considered to be good for their learning and hearing their thoughts can be informative for our professional development. If we give students some space to tell us how and where they learn best, it helps them but it also increases my ability to teach diverse students because I can ask for help from other teachers" (teacher 1 from the developed phase school). In addition, as processes began to reach their cyclical form, pedagogy was no longer seen as 
a particular teaching method, but instead as a common vision in which teachers were seen more like designers and students more like producers and owners of their own learning. In other words, teachers' negotiations had developed to focus more on how to utilise the information received from the students, and less on what the specific practices or subjects of the day were.

Through the cyclical nature of processes, the spaces were used neither as purely fixed nor as experienced anymore, but rather practices were produced through shared experience, which also included the more appropriate role of a material aspect (i.e., the curriculum). As a result, teachers and students, in taking more risks and trying new methods, created opportunities to learn in different physical and virtual spaces inside and outside school. "Once it is at this level, with students having the tools for their learning, they can begin to apply them in different environments in or out of school buildings" (teacher 12 from the developed phase school). Thereby, advanced processes created the opportunity for the expansion of the learning environment in its different forms.

\section{Barriers and facilitators of change}

The meaning-making process (i.e., shared vision) acts as both facilitating and inhibiting the three social interaction processes. To support and guide everyday processes and structuring the space, the vision had to be produced to be shared at different levels. Firstly, the shared vision could be enabling through strategic processes. The importance of sufficient 'structures', such as scheduling and a sufficient number of teachers, was highlighted when arranging new ways to teach and learn. By adjusting the timetables of the whole school, it was "possible to arrange a time for teachers' co-planning and reflection" (principal 1). The autonomy of their own schedules was also important, because it allowed them to tailor the school day for diverse needs. "When we can arrange our own schedules, the skills of special education teachers are available to all students. We must listen to students and we must think together about what our diverse expertise has to offer. However, it strongly demands that we have enough staff and time" (teacher 8 from the developed phase school). Thinking about spaces produced through a meaning-making process provides an opportunity to think about space from the perspective of the student. For instance, space could be produced to provide a permanent smaller group or specific spatial arrangements: "We need to be able to use the space as it serves our students in the best possible ways. It can mean, for example, that we establish a new group for children who need less openness or visual stimulus" (principal 2). Second, by strategic decision making, the shared vision could be supportive. This was important especially in situations described earlier in which teachers did not have tools or resources to begin negotiations. "It was very important that the principal sits with us and asks good questions about routines in new spaces. By these questions, we had to create a common vision, even if we disagreed. In addition, the principal always asked if there was something that had to be done so that it would support our work" (teacher 6 from the developed phase school).

\section{Discussion}

This study examined how, and through which processes, learning spaces are transformed, produced and developed. In line with previous studies (Fenwick 2012; Mulcahy et al. 2015), this study emphasised that expectations or ready-made models, as such, did not fit 
into the new context and that spaces were considered to be produced as social, physical and material aspects interacted together. The present study also supports Deed and Lesko's (2015) findings that maturity of change depends on the constancy of routines and the level of pedagogical certainty. Yet, in this study, maturity was accomplished through two main characteristics. First, change occurred through interaction processes which, by means of thorough development work, gradually received a cyclical form through which teachers and students negotiated meanings for physical spaces by constructing learning environments for diverse users. Second, to achieve deep change, the changes made in learning spaces also required changes in schools' operational culture. The main results of the study are presented in Fig. 2.

\section{From physical spaces to learning environments for diverse users}

The openness of physical learning spaces provided an opportunity to try different approaches to teaching and learning but, to achieve actual change from physical spaces to learning environments, the spaces need to be developed for diverse users by renegotiating meanings for physical aspects of space. The results are in accordance with the strong corpus of literature (Massey 2005; Lefebvre 1991) and previous empirical research (Alterator and Deed 2016; Campbell et al. 2013; Chapman et al. 2015; Deed and Lesko 2015; Mulcahy 2018; Mulcahy et al. 2015; Woolner et al. 2012), which have emphasised the importance of different social relations when developing learning spaces. Empirical studies of these relations, however, mainly have treated the relations as largely separate from each other, without concentrating on the continued and cyclical form between them, which in this study is the main contribution of deep change.

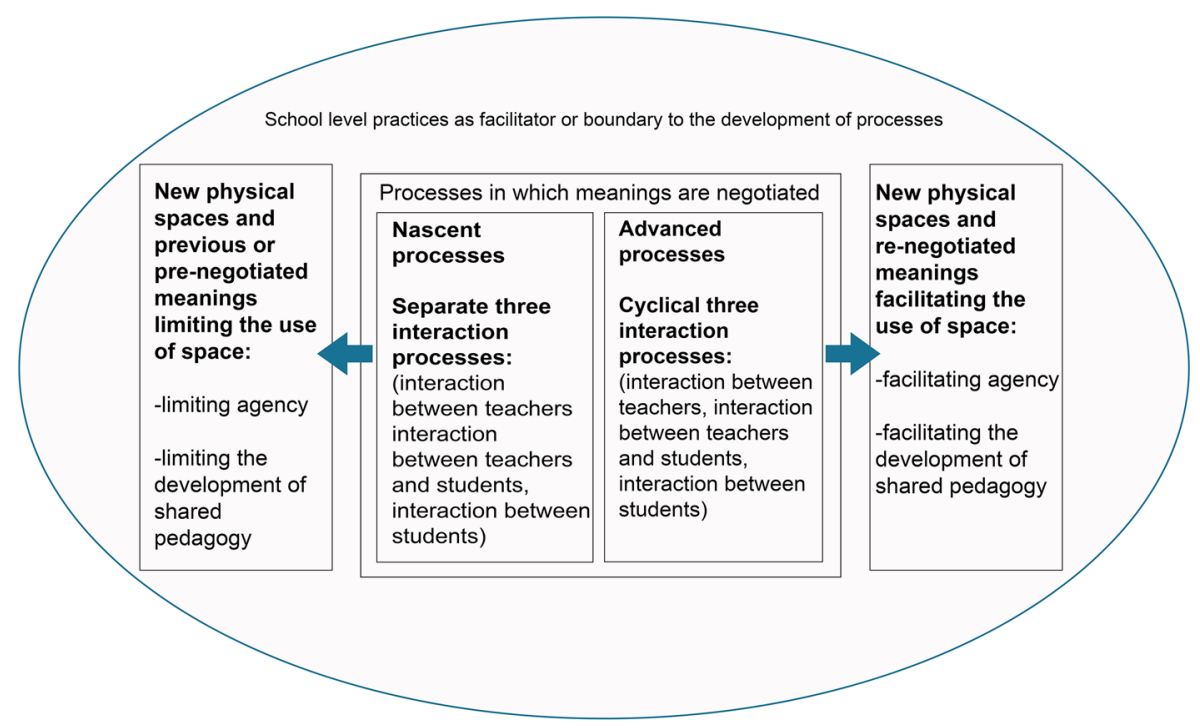

Fig. 2 Main results of the study 
As shown in Fig. 2, activities initially emerged occasionally between teachers, between teachers and students, or between students (i.e., nascent processes). However, mere interaction between teachers, for example, did not automatically produce situations that would necessarily have involved or engaged students in the practice (Woolner et al. 2012). For instance, when the interaction between students was not tied to negotiations with teachers and material aspects, such as the curriculum, students did not necessarily engage in the learning activities. These pre-negotiated situations could also depict students as active agents and owners of their own learning even when they are not. Therefore, the study highlights that, through continuing negotiations in three interaction processes (i.e., interaction between teachers, interaction between students, and interaction between teachers and students), teachers and students created new meanings for physical space, which gradually evolved through cyclicity into advanced processes.

In its more advanced form, information obtained from different interaction processes was continuously utilised to develop daily practices. The major development occurred concerning the structuring of space (Davies et al. 2013; Saltmarsh et al. 2015). In nascent processes structuring, the space was often re-planned but, in advanced processes structuring, it was transformed to be conducted during activities, leaving more space for individual solutions and, therefore, agency. Therefore, through cyclic processes, and with the support from teachers, students negotiated new meanings for their learning and for their experience of emotional security. As a result, students could find tools to build learning environments that suited their diverse needs. In other words, teachers were designers and students were owners of their own learning. This provided the opportunity to expand learning environments inside and outside the school walls into a physical and virtual world, to happen "anytime and anywhere" (Brown and Lippincott 2003).

Conversely, changes made in learning spaces also required changes in the school's operational culture. In other words, a change in practices required an overall change in every aspect of the school (Gislason 2010; Hirsto 2013, 2018; Woolner et al. 2018). In this study, this means that change needed to be produced through shared vision, by supporting negotiations in learning spaces and enabling, through strategic processes, the continued reconstruction of spaces. This was accomplished by a sufficient number of staff in each learning environment, an arrangement for teachers' co-negotiations, and providing autonomy for teachers to arrange their own schedules. In addition, changing school structures based on the needs of students was highly important when constructing shared vision. As a result, a shared vision was not seen as a top-down implementation, but rather as constructed through daily practices and thereby embedded in the school culture and the structures of the school (cf. Gislason 2010; Hirsto 2013; Woolner et al. 2018).

\section{Methodological reflections}

Through two school contexts at different stages of development, we sought to identify the temporal processes of change. The qualitative design and ethnographic comparison of these schools provided an opportunity to open views beyond a single context (Simmons and Smith 2017) and to extend understanding of key processes of change which could be suitable in different contexts. Moreover, the comparison enabled us to explore processes of change by constructing the time window for the first two and a half years of working in new spaces. This means that we could identify specific processes of change from the socialisation phase school, and then confirm them using narratives from the developed 
school. Furthermore, the developed school data also provided the opportunity to examine how processes continued to evolve.

Because we investigated spaces through the relational and sociomaterial approach, we did not attempt to produce direct observations of physical spaces; rather, methods were selected for observing processes between social and physical space. However, the responsive methods (the combination of participant observations and focus-group interviews) used in this study are not likely to be tested in another context or in multiple evaluations over time. Nevertheless, even though this study did not include students' perspectives, the design with these particular methods enabled the use of multiple perspectives (observer, teachers and principals), which together provided an opportunity to produce a richer picture of the phenomenon (Cipriano et al. 2019; Cleveland and Fisher 2014; Newland et al. 2019).

\section{Limitations and future research}

A limitation is that we only drew on material gathered from adults. Yet, the results were discussed concerning students' agency, but the data did not include a students' perspective or the differences between the age groups, which would be an important complementary perspective for the study. Second, change did not happen only with the flexibility of spaces and social processes, but individual teachers also needed to be flexible. Even though our study demonstrates the importance of teachers' deep and continuous negotiations, we did not concentrate on individual teachers' professional learning or their adaptation to the learning spaces and the teacher teams, which could have provided different information on the topic. Therefore, we suggest that future research could continue the investigations of change processes with a student perspective and study differences in these processes between age groups. Moreover, it would be important to concentrate on the successful adaptation and professional development of teachers when moving into new spaces. Finally, although this research provided important evidence by comparing two different contexts, there is a need for further research to confirm these results in other contexts.

\section{Conclusion}

Pre-existing pedagogies or good practices as such cannot be transferred from one space to another, but the construction process of learning space occurred between physical and social (Fenwick 2012; Mulcahy et al. 2015). Therefore, the study is consistent with previous research that has emphasised the importance of social relations in change (Alterator and Deed 2016; Campbell et al. 2013; Chapman et al. 2015; Deed and Lesko 2015; Mulcahy et al. 2015; Woolner et al. 2012), but complements these results by revealing the importance of a cyclic link between the interaction of those relations, especially when pursuing the maturity of change (Deed and Lesko 2015). As a result, teachers and students could transform, develop and construct physical spaces into learning environments for diverse purposes and users.

In addition, by highlighting the systemic perspective to school, this study reinforces the idea of comprehensive change (Gislason 2010; Hirsto 2013, 2018; Woolner et al. 2018) and provides novel and detailed information on how changes in learning spaces also required changes in the schools' operational cultures. Therefore, this study provides an applied agenda for schools to manage continued change in everyday school life. Finally, 
it is important to note that this study focused on the schools' internal processes, however, from a systemic viewpoint, it should be considered [] also how the school is related to a wider environment, including homes, parents and the societal context (Newland et al. 2019; Woolner et al. 2012), which could not be examined in this study.

Acknowledgements Open access funding provided by University of Eastern Finland (UEF) including Kuopio University Hospital. We would like to thank the teachers, principals, and schools that have participated in this research. The manuscript also benefited from the comments of professor Pertti Väisänen. We are also grateful for editors of this journal and anonymous reviewers for their constructive and helpful comments on previous drafts of this article. Part of this research was funded by Olvi-foundation (201820042) and Finnish Ministry of Education research and development grant DigiCampus (OKM/262/523/2017).

Open Access This article is licensed under a Creative Commons Attribution 4.0 International License, which permits use, sharing, adaptation, distribution and reproduction in any medium or format, as long as you give appropriate credit to the original author(s) and the source, provide a link to the Creative Commons licence, and indicate if changes were made. The images or other third party material in this article are included in the article's Creative Commons licence, unless indicated otherwise in a credit line to the material. If material is not included in the article's Creative Commons licence and your intended use is not permitted by statutory regulation or exceeds the permitted use, you will need to obtain permission directly from the copyright holder. To view a copy of this licence, visit http://creativecommons.org/licenses/by/4.0/.

\section{References}

Alterator, S., \& Deed, G. (2013). Teacher adaptation to open learning spaces. Issues in Educational Research, 23(3), 315-330.

Alterator, S., \& Deed, G. (2016). Reacting to "irregular" learning environments in a senior secondary school. Curriculum and Teaching, 31(2), 47-69.

Barret, P., Davies, F., Zhang, Y., \& Barret, L. (2015). The impact of classroom design on pupils' learning: Final results of holistic, multi-level analysis. Building and Environment, 89, 118-133.

Benade, L. (2016). Is the classroom obsolete in the twenty-first century? Educational Philosophy and Theory, 49(8), 796-807.

Blackmore, J., Bateman, D., Loughlin, J., O'Mara, J., \& Aranda, G. (2010). The connection between learning spaces and student learning outcomes: A literature review. Melbourne: Department of Education and Early Childhood Development.

Bohnsack, R. (2004). Group discussion and focus groups. In U. Flick, I. E. Cardorff, \& I. Steinke (Eds.), A companion to a qualitative research (pp. 214-241). London: Sage.

Boys, J. (2011). Where is the theory? In A. Boddington \& J. Boys (Eds.), Re-shaping learning: A critical reader. The future of learning spaces in post-compulsory education (pp. 49-66). Rotterdam: Sense Publisher.

Brooks, D. C. (2011). Space matters: The impact of formal learning environments on student learning. British Journal of Educational Technology, 42(5), 719-726.

Brown, M. B., \& Lippincott, J. K. (2003). Learning spaces: More than meets the eye. Educause Quarterly, $1,14-16$.

Byers, T., Imms, W., \& Hartnell-Young, E. (2014). Making the case for space: The effect of learning spaces on teaching and learning. Curriculum and Teaching, 29(1), 5-19.

Byers, T., Imms, W., \& Hartnell-Young, E. (2018). Comparative analysis of the impact of traditional versus innovative learning environments on student attitudes and learning outcomes. Studies in Educational Evaluation, 58, 167-177.

Campbell, M., Saltmarsh, S., Chapman, A., \& Drew, C. (2013). Issues of teacher professional learning within 'non- traditional' classroom environments. Improving Schools, 16(3), 209-222.

Chapman, A., Randel-Moon, H., Campbell, M., \& Drew, C. (2015). Students in space: Student practices in non-traditional classrooms. Global Studies of Childhood, 4(1), 39-48.

Charmaz, K. (1995). Grounded theory. In J. A. Smith, R. Harre, \& L. Van Langenhove (Eds.), Rethinking methods in psychology (pp. 27-49). London: Sage.

Charmaz, K. (2016). The power of constructivist grounded theory for critical inquiry. Qualitative Inquiry, 23(1), 34-45. 
Cho, Y. (2008). Intercoder reliability. In P. J. Lavrakas (Ed.), Encyclopedia of survey research (pp. 345346). Thousand Oaks, CA: Sage.

Cipriano, C., Barnes, T. N., Pieloch, K. A., Rivers, S. E., \& Brackett, M. (2019). A multilevel approach to understanding student and teacher perceptions of classroom support during early adolescence. Learning Environments Research, 22(2), 209-228.

Cleveland, B. (2009). Engaging spaces: An investigation into middle school educational opportunities provided by innovative built environments: A new approach to understanding the relationship between learning and space. The International Journal of Learning, 16, 385-397.

Cleveland, B., \& Fisher, K. (2014). The evaluation of physical learning environments: A critical view of the literature. Learning Environments Research, 17(1), 1-28.

Davies, D., Jindal-Snape, D., Collier, C., Digby, R., Hay, P., \& Howe, A. (2013). Creative learning environments in education-A systematic literature review. Thinking Skills and Creativity, 8, 80-91.

Deed, C., \& Lesko, T. M. (2015). 'Unwalling' the classroom: Teacher reaction and adaptation. Learning Environments Research, 18(2), 217-231.

Deed, C., Cox, P., Dorman, J., Edwards, D., Farrelly, C., Keeffe, M., et al. (2015). Personalized learning in the open classroom: The mutuality of teacher and student agency. International Journal of Pedagogies and Learning, 9(1), 66-75.

DeVault, M., \& McCoy, L. (2002). Institutional ethnography: Using interviews to investigate ruling relations. In J. Gubrium \& J. Holstein (Eds.), Handbook of interview research: Context and method (pp. 751-776). Thousand Oaks, CA: Sage.

Dovey, K., \& Fisher, K. (2014). Designing for adaptation: The school as socio-spatial assemblage. The Journal of Architecture, 19(1), 43-63.

Fenwick, T. (2012). Sociomaterial approach to conceptualizing professional learning and practice. Journal of Education and Work, 25(1), 1-13.

Gislason, N. (2010). Architectural design and the learning environment: A framework for school design research. Learning Environments Research, 13(2), 127-145.

Hirsto, L. (2013). Palautepohjainen opetuksen kehittäminen ja laatu. In Hakala, J. \& Kiviniemi, K. (Eds.), Vuorovaikutuksen jännitteitä ja oppimisen säröjä. Aikuispedagogiikan haasteiden äärellä (pp. 147-162). Kokkolan yliopistokeskus Chydenius. https://eur03.safelinks.protection.outlo ok.com/?url=http\%3A\%2F\%2Furn.fi\%2FURN\%3AISB N\%3A978-951-39-5376-8\&data=02 \%7C01\%7C\%7C6b25492c34264214bb6d08d7f75edd08\%7C87879f2e73044bf2baf263e7f83f 3c34\%7C0\%7C0\%7C637249859116148640\&sdata=hCpB22ZsYZ46N\%2FdPotjCs1FImzyTPeCS IibNBq\%2BmQOU\%3D\&reserved=0http://urn.fi/URN:ISBN:978-951-39-5376-8

Hirsto, L. (2018). Oppimisympäristöratkaisujen kehittäminen instituution, oppimisen ja pedagogiikan näkökulmasta. In M. Hyypiä, U. Leppänen, S. Hacklin \& P. Korhonen (Eds.), Digitaalisten oppimisympäristöjen kehittämiskeskuksen tiekartta - Roadmap. UEF Electronic Publications. https://eur03 .safelinks.protection.outlook.com/?url=http\%3A\%2F\%2Furn.fi\%2Furn\%3Anbn\%3Afi\%3Auef-20181 $147 \&$ data $=02 \% 7 \mathrm{C} 01 \% 7 \mathrm{C} \% 7 \mathrm{C} 6 \mathrm{~b} 25492 \mathrm{c} 34264214 \mathrm{bb} 6 \mathrm{~d} 08 \mathrm{~d} 7 \mathrm{f} 75 \mathrm{edd} 08 \% 7 \mathrm{C} 87879 \mathrm{f} 2 \mathrm{e} 73044 \mathrm{bf} 2 \mathrm{baf} 263 \mathrm{e}$ 7f83f3c34\%7C0\%7C0\%7C637249859116148640\&sdata=kpIIp3npm8QmnlNcS9xZ5T4kTO\%2FzVE NahgpaJOPfj2k\%3D\&reserved=0http://urn.fi/urn:nbn:fi:uef-20181147

Hultin, L. (2019). On becoming a sociomaterial researcher: Exploring epistemological practices grounded in a relational, performative ontology. Information and Organization, 29(2), 91-104.

Imms, W., \& Byers, T. (2017). Impact of classroom design on teacher pedagogy and student engagement and performance in mathematics. Learning Environments Research, 20(1), 139-152.

Kariippanon, K. E., Cliff, D., Lancaster, S., Okely, A., \& Parrish, A.-M. (2018). Perceived interplay between flexible learning spaces and teaching, learning and student wellbeing. Learning Environments Research, 21(3), 301-320.

Laurie, N. (2012). Towards a comparative ethnography in geography. Annals of Association of American Geographers, 102(2), 500-502.

Lee, N., \& Tan, S. (2011). A comprehensive learning space evaluation model. Strawberry Hills, NSW: Australian Teaching and Learning Council.

Lefebvre, H. (1991). The production of space (D. Nicholson-Smith, Trans.). Malden, MA: Blackwell.

Leiringer, R., \& Cardellino, P. (2011). Schools for the twenty-first century: School design and educational transformation. British Educational Research Journal, 37(6), 915-934.

Massey, D. (2005). For space. London: Sage.

McGregor, J. (2004). Spatiality and the place of the material in schools. Pedagogy, Culture and Society, 12(3), 347-372.

Mills, K., \& Comber, B. (2015). Socio-spatial approaches to literacy studies: Rethinking the social constitution and politics of space. In K. Pahl \& J. Rowsell (Eds.), Handbook of literacy studies (pp. 91-103). London: Routledge. 
Mulcahy, D. (2018). Assembling spaces of learning 'in' museums and schools: A practice-based sociomaterial perspective. In R. A. Ellis \& P. Goodyear (Eds.), Spaces of teaching and learning (pp. 13-29). New York: Springer.

Mulcahy, D., Cleveland, B., \& Aberton, H. (2015). Learning spaces and pedagogical change: Envisioned, enacted and experienced. Pedagogy, Culture and Society, 23(4), 575-595.

Mäkelä, T., Helfenstein, S., Lerkkanen, M. K., \& Poikkeus, A.-M. (2018). Student participation in learning environment improvement: Analysis of a co-design project in a Finnish upper secondary school. Learning Environments Research, 21(1), 19-41.

Newland, L. A., Mourlam, D., Strouse, G., Decino, D., \& Hanson, C. (2019). A phenomenological exploration of children's school life and well-being. Learning Environments Research, 22(3), 311-323.

Owen, S. (2016). Professional learning communities: Building skills, reinvigorating the passion, and nurturing teacher wellbeing and "flourishing", within significantly innovative schooling contexts. Educational Review, 68(4), 403-419.

Picker, G. (2017). Rethinking ethnographic comparison: Two cities, five years, one ethnographer. Journal of Contemporary Ethnography, 46(3), 263-284.

Qu, S., \& Dumay, J. (2011). The qualitative research interviews. Qualitative Research in Accounting and Management, 8(3), 238-264.

Radcliffe, D. (2008). A pedagogy-space-technology (PST) framework for designing and evaluating learning places. In D. Radcliffe, W. Wilson, D. Powell, \& B. Tibbetts (Eds.), Learning spaces in higher education: Positive outcomes by design. Brisbane: The University of Queensland.

Ryan, R., \& Deci, E. (2000). Self-determination theory and the facilitation of intrinsic motivation, social development, and well-being. American Psychologist, 55(1), 68-78.

Saltmarsh, S., Chapman, A., Campbell, M., \& Drew, C. (2015). Putting "structure within the space": Spatially un/responsive pedagogic practices in open-plan learning environments. Educational Review, $67(3), 315-327$.

Schatz, E. (2009). Ethnographic Immersion and the study of politics. In E. Schatz (Ed.), Political ethnography: What immersion contributes to the study of politics (pp. 1-22). Chicago: University of Chicago Press.

Scherzinger, M., \& Wettstein, A. (2019). Classroom disruptions, the teacher-student relationship and classroom management from the perspective of teachers, students and external observers: A multimethod approach. Learning Environments Research, 22(1), 101-116.

Simmons, E., \& Smith, N. R. (2017). Comparison with an ethnographic sensibility. Political Science and Politics, 50(1), 126-130.

Simmons, E., \& Smith, N. R. (2019). The case for comparative ethnography. Comparative Politics, 51(3), $341-359$.

Strauss, A., \& Corbin, J. (1994). Grounded theory methodology: An overview. In N. Denzin \& Y. Lincoln (Eds.), Handbook of qualitative research (pp. 273-285). Thousand Oaks, CA: Sage.

Strauss, A., \& Corbin, J. (1998). Basics of qualitative research: Techniques and procedures for developing grounded theory (2nd ed.). Thousand Oaks, CA: Sage.

Taylor, L. (2013). The case as space: Implications of relational thinking for methodology and method. Qualitative Inquiry, 19(10), 807-817.

Watson, C. (2014). Effective professional learning communities? The possibilities for teachers as agents of change in schools. British Educational Research Journal, 40(1), 18-29.

Woolner, P., McCarter, S., Wall, K., \& Higgins, S. (2012). Changed learning through changed space: When can a participatory approach to the learning environment challenge preconceptions and alter practice? Improving Schools, 15(1), 45-60.

Woolner, P., Thomas, U., \& Tiplady, L. (2018). Structural change from physical foundations: The role of the environment in enacting school change. Journal of Educational Change, 19(2), 223-242.

Publisher's Note Springer Nature remains neutral with regard to jurisdictional claims in published maps and institutional affiliations. 